\title{
Methylation and expression of RECK, P53 and RUNX genes in patients with esophageal cancer
}

\author{
YANRONG LU ${ }^{1}$, BAERXIAGULI ZABIHULA ${ }^{1}$, WARESIJIANG YIBULAYIN ${ }^{2}$ and XIANG LIU ${ }^{3}$ \\ Departments of ${ }^{1}$ Thoracico-Abdominal Radiotherapy, ${ }^{2}$ Thoracic Surgery and ${ }^{3}$ Medical Administration Management, \\ Tumor Hospital Affiliated to Xinjiang Medical University, Ürümqi, Xinjiang 830011, P.R. China
}

Received April 3, 2017; Accepted August 17, 2017

DOI: $10.3892 / \mathrm{ol} .2017 .6863$

\begin{abstract}
The methylation and expression of RECK, P53 and $R U N X$ genes in patients with esophageal cancer was investigated. In order to achieve this aim, a sample of 58 patients with esophageal cancer, treated between February 2013 and February 2014, were considered as the observation group. Additionally, a sample of 42 healthy individuals was selected as the control group. Methylation status of RECK, P53 and RUNX genes from the observation and control groups were detected by MSP. Reverse transcriptase-quantitative PCR (RT-qPCR), enzyme-linked immunosorbent assay (ELISA), western blot and immunohistochemistry were used to detect the mRNA and protein levels of RECK, P53 and RUNX in both the observation and the control groups. Results showed that the methylation rates of RECK, P53 and RUNX genes in patients with esophageal cancer were $72.4 \%$ (42/58), $1.7 \%$ (1/58) and 3.4\% (2/58), respectively, which were significantly different from those in the control group [7.1\% (3/42), 90.5 (38/42), and 83.3\% (35/42), respectively]. The mRNA expression level of RECK is only equal to the $2.3 \%$ of that in the control group, while the mRNA expression levels of P53 and RUNX were 65.1 and 47.2 times higher than those in the control group, respectively $(\mathrm{p}<0.05)$. ELISA showed that RECK protein level in the observation group $(0.12 \pm 0.05) \mu \mathrm{g} / \mathrm{l}$, was significantly lower than the control group $(3.46 \pm 0.08) \mu \mathrm{g} / 1(\mathrm{p}<0.05)$, while, P53 and RUNX protein levels in observation group were significantly higher than that in healthy people $(6.43 \pm 0.12 \mu \mathrm{g} / 1$ vs. $0.64 \pm 0.06 \mu \mathrm{g} / 1$ and $4.32 \pm 0.14 \mu \mathrm{g} / \mathrm{l}$ vs. $0.53 \pm 0.09 \mu \mathrm{g} / \mathrm{l}$, respectively), and the results were similar to western blot. The data of immunohistochemistry showed that the proportion of RECK protein positive cells in the observation group was significantly lower than that in the control group (9.5 vs. $82.3 \%, \mathrm{P}<0.05$ ), while the proportions of P53 and RUNX protein positive cell in the observation group were significantly higher than those in the control group (78.4
\end{abstract}

Correspondence to: Dr Baerxiaguli Zabihula, Department of Thoracico-Abdominal Radiotherapy, Tumor Hospital Affiliated to Xinjiang Medical University, 789 Suzhou East Street, Ürümqi, Xinjiang 830011, P.R. China

E-mail: b7x74p@163.com

Key words: esophageal cancer, RECK, P53, RUNX, methylation vs. $11.1 \%$ and 87.3 vs. $9.06 \%)$, respectively, $(\mathrm{P}<0.05)$. This study concluded that, in patients with esophageal cancer, the methylation of $R E C K$ gene is increased and the expression of $R E C K$ gene is inhibited, while methylation of $R U N X$ gene decreased and their expression was increased. This change in methylation of these genes may promote the occurrence and development of esophageal cancer.

\section{Introduction}

The increasing incidence of esophageal cancer has led to its becoming one of the common digestive diseases (1), and in fact, was the sixth most common cancer disease in China by the end of 2015 (2) causing the fourth highest mortality rates among all cancer diseases (2).

Methylation plays an important role in the development and progression of tumors. Previous studies showed that the increased methylation rate of the tumor suppressor gene rate and its promoter region can significantly increase the occurrence of the tumor (3). The methylation rate of $\mathrm{CDHl}$ gene in esophageal cancer patients is approximately $12.3 \%$, compared to $73.4 \%$ in healthy individuals and this reduced gene methylation can promote gene expression (4). Thus, the levels of related oncogene proteins are increased. Previous findings have shown significantly higher expression levels of RUNX3 and P53 in cancer cells compared to those in healthy cells (5). The main function of RUNX3 gene is to bind DNA to form a complex to inhibit or promote the process of cell growth and differentiation (6). P53 gene is a common transcription factor (7) and the expression of P53 in healthy cells is normally low, but when the cells are stimulated by toxic substances or carcinogenic factors, the expression rapidly increases and thus makes P53 closely related to the development of cancer. As a newly discovered tumor inhibitor (8), RECK can inhibit tumor cell infiltration.

In this study, we explored the relationship between $R E C K$, $P 53$ and RUNX gene methylation and esophageal cancer to reveal the interactions between them and to provide the theoretical and the experimental basis for the diagnosis and treatment of esophageal cancer.

\section{Materials and methods}

General information. In total, 58 esophageal cancer patients (28 males, 30 females) with an average age of $32.4 \pm 15.3$ 
years were selected during the period of February 2013 to February 2014 and 58 healthy inidivduals (21 males, 21 females) with a mean age of $33.2 \pm 12.4$ years were also considered as control group. All the patients signed informed consent and the study was approved by the Ethics Committee of the Tumor Hospital Affiliated to Xinjiang Medical University (Xinjiang, China). Inclusion criteria for the study were: a) suffering from esophageal cancer, and b) aged between 32 and 65 years. The exclusion criteria were a) suffering from other tumors and cancer, b) suffering from digestive system diseases, and c) $<32$ or $>65$ years of age, and d) other reasons.

Main reagents and instruments. The following main reagents were used: RNA Extraction kit (Xinmai Biotechnology Co., Ltd., Shanghai, China), RT-qPCR kit (Applied Biosystems, Foster City, CA, USA), rabbit anti-human RECK, P53, and RUNX monoclonal primary antibody (Acris Antibodies Inc., San Diego, CA, USA), mouse anti-rabbit polyclonal secondary antibody (HRP-labeled) (Genewiz, Suzhou, China), primary antibody and secondary antibody of GAPDH were purchased from Thermo Fisher Scientific (Waltham, MA, USA), immunohistochemistry kit (Roche, Indianapolis, IN, USA), ELISA kit (Takara, Dalian, China), methylation determination kit (Kang Century Biotech Co., Ltd., Beijing, China) and other chemical reagents were from Sinopharm Chemical Reagent Co., Ltd. (Shanghai, China). In addition, the following main instruments were used: Fluorescence quantitative PCR instrument (Applied Biosystems), microplate reader (Beijing Liuyi Biotechnology, Beijing, China), protein electrophoresis (Beijing Liuyi Biotechnology), gel imager (Bio-Rad, Hercules, CA, USA), Olympus microscope X53, Mindrop micro-nucleic acid quantitative instrument (Bio-Rad).

Methylation detection. The total DNA was extracted and processed by methylation assay kit according to the instructions. The specific methylation primers were designed according to the methylation principle. Table I shows the primer sequences.

\section{$R T-q P C R$}

$R N A$ extraction. In order to extract RNA, the digestive tract samples were collected from both patients and healthy people, then stored in liquid nitrogen or in a refrigerator at $-80^{\circ} \mathrm{C}$. Then $0.5 \mathrm{~g}$ of the sample was mixed with $300 \mu \mathrm{l}$ RNA Plus by pipetting and was kept at room temperature for $10 \mathrm{~min}$, followed by centrifugation $(10,000 \mathrm{xg})$ at $4^{\circ} \mathrm{C}$ for $5 \mathrm{~min}$. The supernatant was collected and $250 \mu \mathrm{l}$ chloroform was added. After vigorous mixing, the mixture was kept at room temperature for $5 \mathrm{~min}$. After centrifugation $(10,000 \mathrm{x} \mathrm{g})$ at $4{ }^{\circ} \mathrm{C}$ for $5 \mathrm{~min}$, the supernatant was collected and then an equal volume of isoamyl alcohol was added and mixed gently, followed by centrifugation $(10,000 \mathrm{xg})$ at $4^{\circ} \mathrm{C}$ for $10 \mathrm{~min}$. Then the supernatant was removed and the sample was washed with $75 \%$ ethanol 2 or 3 times. The samples were placed at room temperature until the ethanol was completely removed. Then $50 \mu \mathrm{l}$ of RNase-free ultra-pure water was added and the mass of the RNA extracted was quantitated by the Mindrop microarray and analyzed by electrophoresis (9).

Fluorescence quantitation. All the operations were performed according to the instructions of Takara fluorescence
Table I. Methylation primers.

\begin{tabular}{ll}
\hline Primer name & \multicolumn{1}{c}{ Sequences } \\
\hline RECK-F & ATCTACTATTCCTCTATCTATCCAC \\
RECK-R & CTATCTATTCATCTTCTATCTACC \\
P53-F & CTATCTTATCTATCTTCTCTATCTTC \\
P53-R & CTATCTTATCTTCTCTCATCTCTAC \\
RUNX-F & CTATCTTTATACTATCTTCTCTATC \\
RUNX-R & TCTCTCTATTATCTTAAACTTCTAC
\end{tabular}

Table II. q-RT-PCR primers.

\begin{tabular}{ll}
\hline Primer name & \multicolumn{1}{c}{ Sequences } \\
\hline RECK-F & AGCTGATGCATCGATCGATCGATC \\
RECK-R & CGTATCGTGGTCAGTCGTACGTCAC \\
P53-F & AGTCGATGCTAGCTAGCTAGCTAC \\
P53-R & TGATCGATCGATGATAGTACACGC \\
RUNX-F & TGATGCGCGCTAGCATGAAGTCGATCG \\
RUNX-R & CTGATCGGAGATCAGTCAGCGATCAGCTG \\
GAPDH-F & GTCGATGGCTAGTCGTAGCATCGAT \\
GAPDH-R & TGCTAGCTGGCATGCCCGATCGATC \\
\hline
\end{tabular}

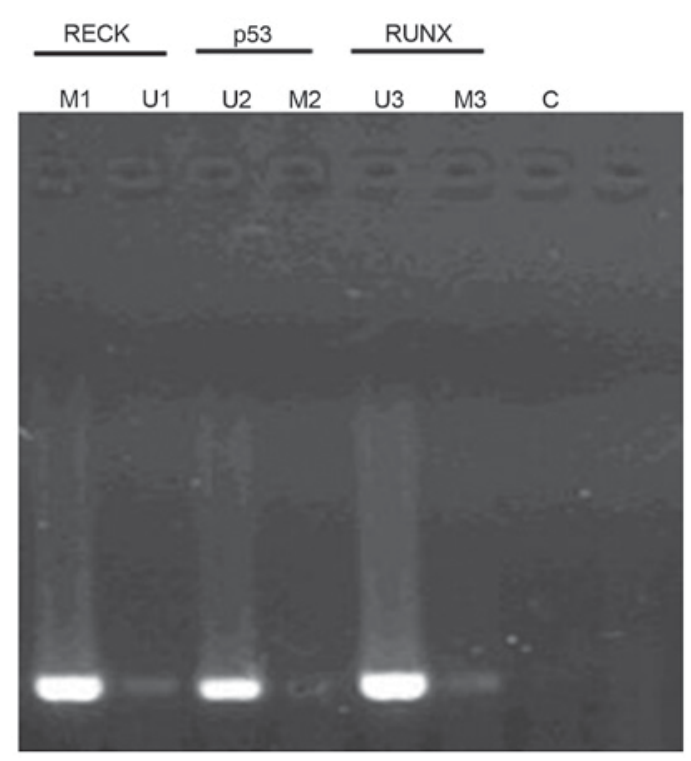

Figure 1. Methylation status of different genes in different samples, where M1, amplification result of RECK methylation primer; U1, amplification result of RECK non-methylation primer; M2, amplification result of P53 methylation primer; U2, amplification result of P53 non-methylation primer; M3, amplification result of RUNX methylation primer; U3, amplification result of RUNX non-methylation primer; $\mathrm{C}$, water as template.

quantitative PCR. Furthermore, the PCR primers were synthesized by the Sangon Biotech (Shanghai, China) (Table II).

Cell total protein extraction. The esophageal cancer samples were collected from patients with esophageal cancer and 

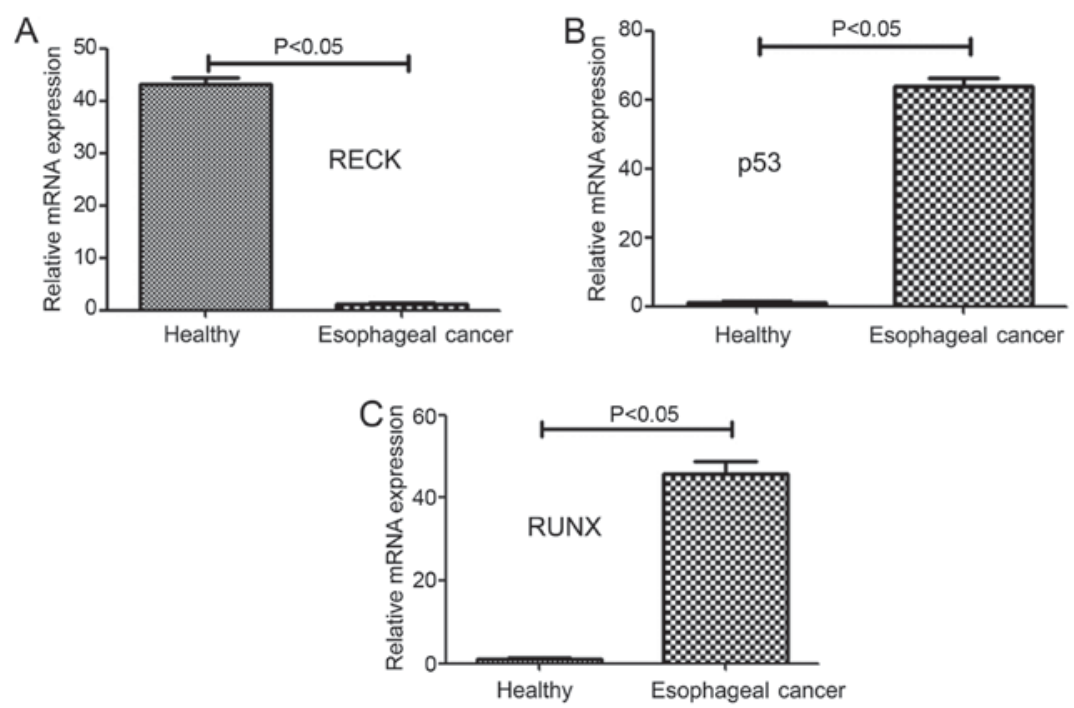

Figure 2. The mRNA levels of different genes in patients with esophageal cancer and healthy people. (A) Relative mRNA level of RECK in patients with esophageal cancer and healthy people. (B) Relative mRNA level of p53 in patients with esophageal cancer and healthy people. (C) Relative mRNA level of RUNX in patients with esophageal cancer and healthy subjects.

from healthy subjects and then preserved in liquid nitrogen. After melting ice, reaction solution A was quickly added and the mixture was vigorously mixed for 2-3 min. Then reaction mixture $\mathrm{B}$ was added and mixed gently followed by centrifugation $(12,000 \mathrm{xg})$ at $4^{\circ} \mathrm{C}$ for $10 \mathrm{~min}$. The supernatant was kept.

Enzyme-linked immunosorbent assay (ELISA). The expression of different gene proteins in different samples was detected by ELISA kit (Takara). The main steps are as follows: the standard protein samples were first diluted at 1:50 with dilution buffer in the kit and a standard curve was drawn. The sample to be tested was then diluted at the ratio of 1:100 with PBS (pH 7.2) and then $100 \mu 1$ solution was added to each well. Test solution $(50 \mu \mathrm{l})$ was added and incubated at room temperature for $2 \mathrm{~h}$ and TMB chromogenic substrate was added. The absorbance values were measured at $495 \mathrm{~nm}$, and the protein concentration in each sample was calculated according to the standard curve given previously (10).

Western blotting. In order to determine the protein expression of different genes in different samples, western blotting was used. The total protein extracted from the samples was quantified by Coomassie blue staining. Processed sample $(20 \mu \mathrm{l})$ was subjected to SDS-PAGE electrophoresis and then protein was transferred to the membrane by the semi-dry method. The membrane was blocked with $1 \%$ skim milk for $2 \mathrm{~h}$. The primary antibody was diluted with a ratio of 1:1,000, and then was added and incubated at room temperature for $2 \mathrm{~h}$. Membranes were first incubated with primary rabbit monoclonal Reck antibody (dilution: 1:500; cat. nos. ab115844), rabbit monoclonal p53 antibody (dilution: 1:500; cat. nos. ab32049) and rabbit polyclonal Runx antibody (dilution: 1:500; cat. nos. ab23981) at $20^{\circ} \mathrm{C}$ for $2 \mathrm{~h}$, and then incubated with secondary goat antirabbit (HRP) IgG antibody (dilution: 1:2000; cat. nos. ab6721). The antibodes were purchased from Abcam (Cambridge, MA, USA). The membrane was washed 5 times (10 min each time) and color development solution was added (11).
Immunohistochemistry. The digestive tract samples were collected from both patients and healthy people and were stored in liquid nitrogen or at $-80^{\circ} \mathrm{C}$. The samples were processed according to the experimental procedure described by Shi et al $(12,13)$. The positive rate was determined by immunoassay kit according to the instructions of the kit.

Statistical analysis. Data were analyzed using SPSS 19.0 software (IBM, Armonk, NY, USA). The Chi-square test was used to compare the statistical data considering the level of significance $\alpha=0.05$.

\section{Results}

Methylation of different genes in different samples. Fig. 1 shows the methylation status of different genes in different samples by MSP method (methylation-specific PCR). The methylation rates of RECK, P53 and RUNX genes in patients with esophageal cancer were $72.4 \%$ (42/58), $1.7 \%(1 / 58)$ and $3.4 \%(2 / 58)$, respectively; while the methylation rates of RECK, P5 and RUNX in healthy tissue were 7.1\% (3/42), 90.5\% (38/42) and 83.3\% (35/42), respectively. Furthermore, there were significant differences between patients and healthy people $(\mathrm{P}<0.05)$.

$m R N A$ levels of different genes in patients with esophageal cancer and healthy people. The mRNA expression levels of different genes in patients with esophageal cancer and healthy subjects were determined by RT-qPCR, as shown in Fig. 2A-C. The mRNA level of RECK in patients with esophageal cancer was found significantly lower (approximately $2.3 \%$ of the RECK mRNA level in healthy subjects) than that of healthy subjects $(\mathrm{P}<0.05)$ (Fig. 2A). Moreover, the mRNA level of P53 in patients with esophageal cancer was significantly higher than that of healthy subjects $(\mathrm{P}<0.05)$ (Fig. 2B). Finally, the mRNA level of RUNX in patients with esophageal cancer was 47.2 times higher than that of healthy subjects and this difference was statistically significant $(\mathrm{P}<0.05)$ (Fig. 2C). 

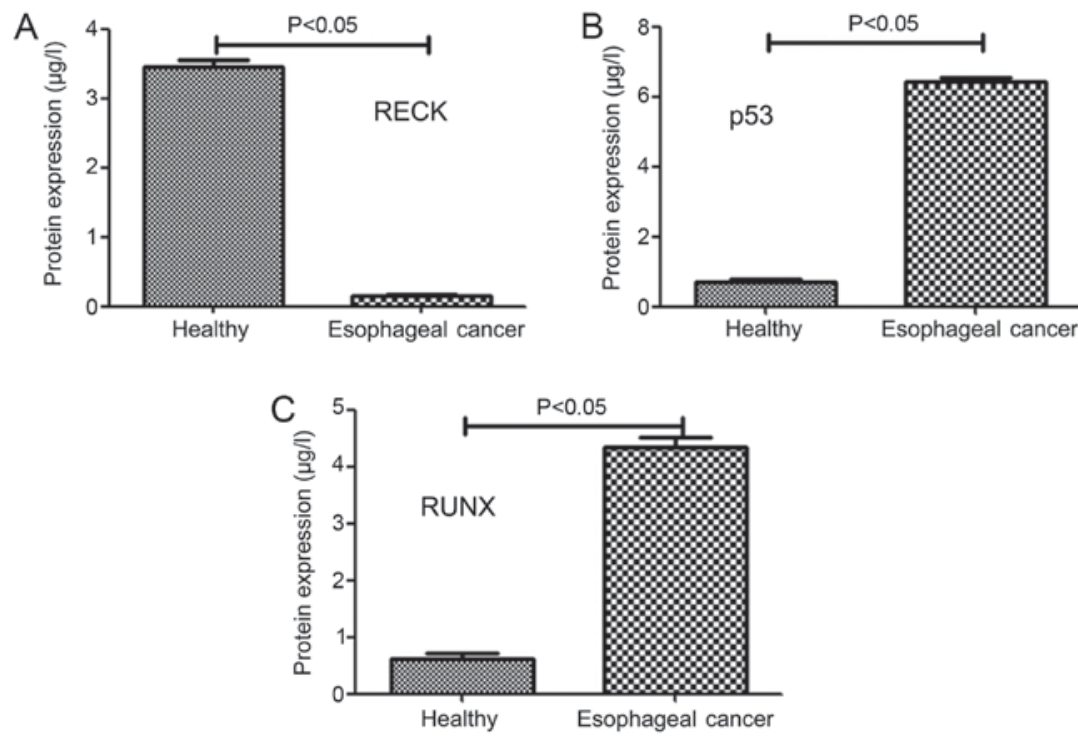

Figure 3. Protein levels of different genes in patients with esophageal cancer and healthy subjects detected by ELISA assay. The protein level of (A) RECK, (B) P53, and (C) RUNX.

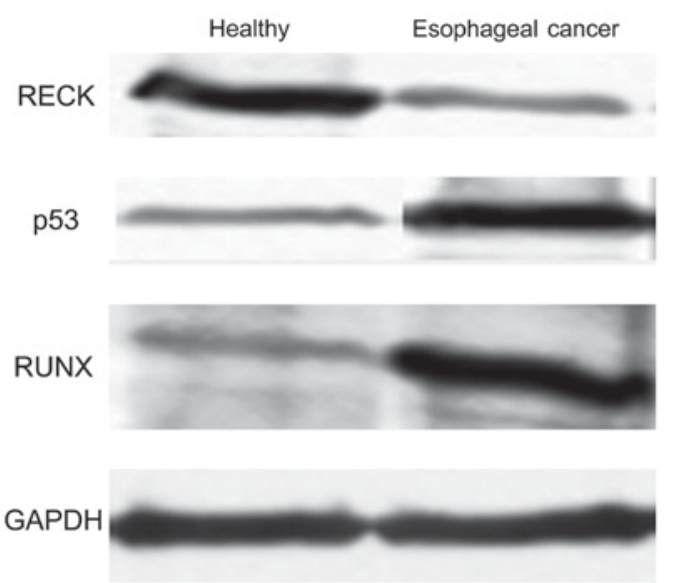

Figure 4. Protein levels of the genes in different samples detected by western blotting. The level of RECK protein was significantly higher in the healthy subjects than that in the patients with esophageal cancer, whereas protein levels of P53 and RUNX in patients with esophageal cancer were significantly higher than those in healthy subjects.

Protein levels of different genes in patients with esophageal cancer and healthy people. Herein, ELISA was used to detect the protein levels of different genes in different samples and the results are shown in Fig. 3A-C. The protein level of RECK in patients with esophageal cancer $(0.12 \pm 0.05 \mu \mathrm{g} / \mathrm{l})$ was significantly lower than that in healthy people $(3.46 \pm 0.08 \mu \mathrm{g} / \mathrm{l})$, $(\mathrm{P}<0.05)$ (Fig. 3A) Moreover, the protein levels of P53 and RUNX patients with esophageal cancer and healthy people $(6.43 \pm 0.12 \mu \mathrm{g} / 1$ and $4.32 \pm 0.14 \mu \mathrm{g} / \mathrm{l})$ were significantly higher than those of healthy subjects $(0.64 \pm 0.06 \mu \mathrm{g} / 1$ and $0.53 \pm 0.09 \mu \mathrm{g} / \mathrm{l})(\mathrm{P}<0.05)$ (Fig. 3B and $\mathrm{C})$.

Protein levels of different genes in different samples detected by western blotting. In order to determine further the differences in protein expression between healthy individuals and patients with esophageal cancer, different levels of genes in both groups were determined by western blot. As shown in
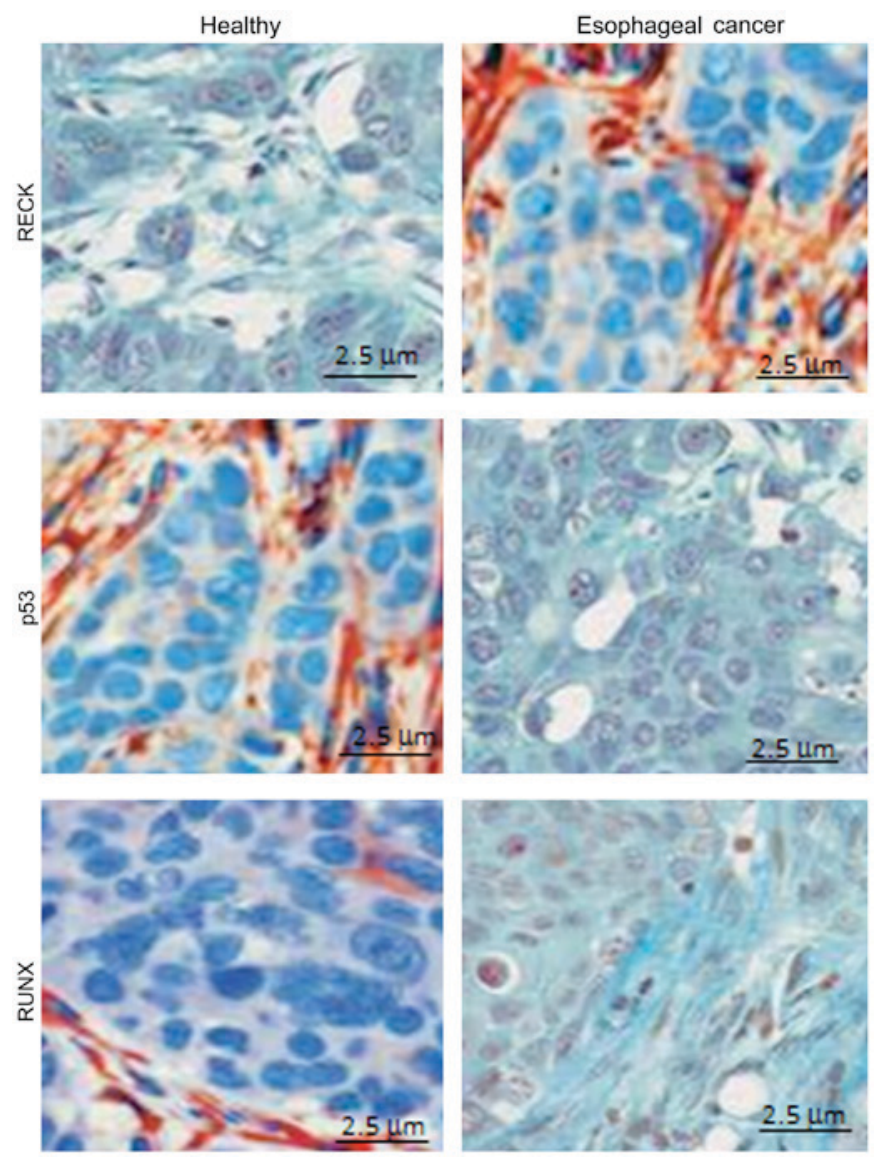

Figure 5. Positive expression rate of RECK, P53 and RUNX in the samples detected by immunohistochemical method (x50).

Fig. 4, the level of RECK protein was significantly higher in the healthy people than that in the patients with esophageal cancer $(\mathrm{p}<0.05)$, whereas protein levels of P53 and RUNX in patients with esophageal cancer were significantly higher than those in healthy people $(\mathrm{p}<0.05)$. In addition, western blot results were consistent with ELISA results. 
Table III. A summary of the positive expression rate of different genes in the samples.

\begin{tabular}{lcccc}
\hline Group & $\begin{array}{c}\text { Cell } \\
\text { number } \\
\text { (n) }\end{array}$ & $\begin{array}{c}\text { Positive } \\
\text { rate of } \\
\text { RECK (\%) }\end{array}$ & $\begin{array}{c}\text { Positive } \\
\text { rate of } \\
\text { P53 (\%) }\end{array}$ & $\begin{array}{c}\text { Positive } \\
\text { rate of } \\
\text { RUNX (\%) }\end{array}$ \\
\hline Control group & 400 & 82.3 & 11.1 & 9.06 \\
Observation group & 400 & 9.5 & 78.4 & 87.3 \\
P-value & & $<0.001$ & $<0.001$ & $<0.001$ \\
\hline
\end{tabular}

Positive expression of different genes in different samples detected by immunohistochemical method. Using immunohistochemistry, we detected the positive expression of different genes in different samples. The results showed that RECK protein was mainly expressed in the cytoplasm, and the positive expression rate of RECK in healthy subjects $(82.3 \%)$ was significantly higher than that in patients with esophageal cancer $(9.5 \%)(\mathrm{P}<0.05)$ (Fig. 5A). Moreover, P53 protein was mainly expressed in the cytoplasm, and the positive expression rate of P53 in healthy subjects (11.1\%) was significantly lower than that in patients with esophageal cancer $(78.4 \%)(\mathrm{P}<0.05)$ (Fig. 5B). Furthermore, RUNX protein was mainly expressed in the cytoplasm, and the positive expression rate of RUNX in healthy subjects $(9.06 \%)$ was significantly lower than that in patients with esophageal cancer $(87.3 \%)(\mathrm{P}<0.05)$ (Fig. 5C) (Table III).

\section{Discussion}

Studies on different tumors and cancers have shown that tumor cells and cancer cells are affected by a variety of factors including environmental factors such as various toxic and hazardous substances, radioactive carcinogens, and self-factors such as autoimmune disorders, mutations in tumor suppressor gene and oncogene activation (14). In addition, the environmental factors can affect the expression of intracellular genes to promote the occurrence of cancer cells and tumor cells. Recent findings have identified many tumor suppressor genes in human cells (15). Tumor suppressor genes can also maintain body health by inhibiting the expression of oncogenes. In addition, tumor suppressor genes can be inactivated by mutations within them or the abnormal regulation network, leading to the occurrence of cancer cells and tumor cells. Ethanol and other chemicals can significantly increase the methylation rate of the promoter of human aldehyde dehydrogenase gene, while the accumulation of acetaldehyde can damage the function of liver cells (16).

In previous studies, it was found that the RECK gene, which is highly expressed in normal tissue, can negatively regulate the expression of oncogenes (17). Moreover, the RECK can inhibit angiogenesis. In the present study, we found that methylation rate of $R E C K$ gene in patients with esophageal cancer was significantly higher than that of normal people, indicating that the methylation of $R E C K$ gene can promote the occurrence and development of esophageal cancer. It is well-known that the P53 gene, which is involved in the process of cell signal transduction in cancer cells, can inhibit the occurrence of cancer cells by interacting with carcinogenic factors $(18,19)$. In addition, the $R U N X$ gene, which acts as a downstream regulator of TGF- $\beta$, can promote abnormal cell proliferation and tumor cell infiltration (20). Our results showed that the methylation rates of P53 and $R U N X$ genes in patients with esophageal cancer were significantly reduced, leading to the increased expression of the two genes in esophageal cancer cells, which in turn promote the proliferation and infiltration of esophageal cancer cells. In conclusion, the increased methylation of RECK gene and the decreased methylation of $P 53$ and $R U N X$ genes can promote the occurrence of esophageal cancer.

\section{References}

1. Sottocornola R, Royer C, Vives V, Tordella L, Zhong S, Wang Y, Ratnayaka I, Shipman M, Cheung A, Gaston-Massuet C, et al: ASPP2 binds Par-3 and controls the polarity and proliferation of neural progenitors during CNS development. Dev Cell 19: 126-137, 2010.

2. Xie T, Cui X, Zheng H, Chen D, He L and Jiang B: Meta-analysis: Eradication of Helicobacter pylori infection is associated with the development of endoscopic gastroesophageal reflux disease. Eur J Gastroenterol Hepatol 25: 1195-1205, 2013.

3. Mhaskar RS, Ricardo I, Azliyati A, Laxminarayan R, Amol B, Santosh W and Boo K: Assessment of risk factors of Helicobacter pylori infection and peptic ulcer disease. J Glob Infect Dis 5: 60-67, 2013.

4. Jarl J and Gerdtham UG: Time pattern of reduction in risk of oesophageal cancer following alcohol cessation - a meta-analysis. Addiction 107: 1234-1243, 2012.

5. Venerito M, Kohrs S, Wex T, Adolf D, Kuester D, Schubert D, Peitz U, Mönkemüller K and Malfertheiner P: Helicobacter pylori infection and fundic gastric atrophy are not associated with esophageal squamous cell carcinoma: A case-control study. Eur J Gastroenterol Hepatol 23: 859-864, 2011.

6. Wu R, Jiang Y, Wu Q, Li Q, Cheng D, Xu L, Zhang C, Zhang M and Ye L: Diagnostic value of microRNA-21 in the diagnosis of lung cancer: Evidence from a meta-analysis involving 11 studies. Tumour Biol 35: 8829-8836, 2014.

7. Hu J, Cheng Y, Li Y, Jin Z, Pan Y, Liu G, Fu S, Zhang Y, Feng K and Feng Y: microRNA-128 plays a critical role in human non-small cell lung cancer tumourigenesis, angiogenesis and lymphangiogenesis by directly targeting vascular endothelial growth factor-C. Eur J Cancer 50: 2336-2350, 2014.

8. Jiang T, Tang HM, Lu S, Yan DW, Yang YX and Peng ZH: Up-regulation of tripartite motif-containing 29 promotes cancer cell proliferation and predicts poor survival in colorectal cancer. Med Oncol 30: 715, 2013.

9. Solomon H, Buganim Y, Kogan-Sakin I, Pomeraniec L, Assia Y, Madar S, Goldstein I, Brosh R, Kalo E, Beatus T, et al: Various p53 mutant proteins differently regulate the Ras circuit to induce a cancer-related gene signature. J Cell Sci 125: 3144-3152, 2012

10. Jia G1, Stormont RM, Gangahar DM and Agrawal DK: Role of matrix Gla protein in angiotensin II-induced exacerbation of vascular calcification. Am J Physiol Heart Circ Physiol 303: H523-H532, 2012.

11. Olesen M, Skov V, Mechta M, Mumm BH and Rasmussen LM: No influence of OPG and its ligands, RANKL and TRAIL, on proliferation and regulation of the calcification process in primary human vascular smooth muscle cells. Mol Cell Endocrinol 362. 149-156, 2012.

12. Shi HJ, Wen JK, Miao SB, Liu Y and Zheng B: KLF5 and hhLIM cooperatively promote proliferation of vascular smooth muscle cells. Mol Cell Biochem 367: 185-194, 2012.

13. Sehgal S, Kaul S, Gupta BB and Dhar MK: Risk factors and survival analysis of the esophageal cancer in the population of Jammu, India. Indian J Cancer 49: 245-250, 2012.

14. Shanahan CM, Crouthamel MH, Kapustin A and Giachelli CM: Arterial calcification in chronic kidney disease: Key roles for calcium and phosphate. Circ Res 109: 697-711, 2011.

15. Zhou JY, Chen X, Zhao J, Bao Z, Chen X, Zhang P, Liu ZF and Zhou JY: MicroRNA-34a overcomes HGF-mediated gefitinib resistance in EGFR mutant lung cancer cells partly by targeting MET. Cancer Lett 351: 265-271, 2014. 
16. Steinmetz CG, Xie P, Weiner H and Hurley TD: Structure of mitochondrial aldehyde dehydrogenase: The genetic component of ethanol aversion. Structure 5: 701-711, 1997.

17. Kapustin AN, Davies JD, Reynolds JL, McNair R, Jones GT, Sidibe A, Schurgers LJ, Skepper JN, Proudfoot D, Mayr M, et al: Calcium regulates key components of vascular smooth muscle cell-derived matrix vesicles to enhance mineralization. Circ Res 109: e1-e12, 2011.

18. Toko H, Takahashi H, Kayama Y, Oka T, Minamino T, Okada S, Morimoto S, Zhan DY, Terasaki F, Anderson ME, et al: $\mathrm{Ca}^{2+} /$ calmodulin-dependent kinase IIdelta causes heart failure by accumulation of p53 in dilated cardiomyopathy. Circulation 122: 891-899, 2012
19. Kapustin AN, Davies JD, Reynolds JL, McNair R, Jones GT, Sidibe A, Schurgers LJ, Skepper JN, Proudfoot D, Mayr M, et al: Calcium regulates key components of vascular smooth muscle cell-derived matrix vesicles to enhance mineralization. Circ Res 109: e1-e12, 2011.

20. Speer MY, Li X, Hiremath PG and Giachelli CM: Runx2/Cbfa1, but not loss of myocardin, is required for smooth muscle cell lineage reprogramming toward osteochondrogenesis. J Cell Biochem 110: 935-947, 2010. 